\title{
PERENCANAAN MASTER PLAN ARSITEKTUR BISNIS PT. GLOBAL ARTA BORNEO MENGGUNAKAN FRAMEWORK WARD AND PEPPARD
}

\author{
Abdullah Ardi ${ }^{1}$, Ema Utami ${ }^{2}$, dan Emha Taufiq Luthfi ${ }^{3}$

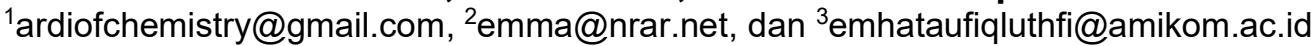 \\ 1,2,3 Universitas AMIKOM Yogyakarta
}

\begin{abstract}
Abstrak
PT. Global Arta Borneo merupakan pemegang Izin Usaha Niaga Umum BBM Migas. Perusahaan tersebut bergerak dalam bidang Hilir Migas melalui Undang-Undang 22/2001 tentang Minyak dan Gas Bumi dan Peraturan Pemerintah 36/2004, serta Surat Izin Usaha Perdagangan No. 510/MP.1106504/PERINDAG. Tujuan dari penelitian ini adalah untuk menentukan strategi yang dapat dikembangkan dalam perancangan SI/TI di PT. Global Arta Borneo. Penyelarasan strategi SI/TI dalam mendukung tujuan organisasi untuk mencapai keunggulan yang kompetitif dan meningkatkan daya saing, dilakukan dengan pendekatan Ward and Peppard Framework menggunakan metode analisis Five Force Factors, PEST, CSF, Value Chain serta McFarlan. Hasil penelitian menujukkan terdapat 10 strategi rencana kegiatan yang ditunjukkan dengan roadmap Teknologi Informasi dan sistem informasi yang akan dibangun dalam jangka waktu 5 tahun.
\end{abstract}

Kata kunci: Strategi SI/TI, Ward and Peppard.

\section{Pendahuluan}

Perkembangan Information System/Information Technology (yang selanjutnya disingkat sebagai IS/IT) dewasa ini berkembang sangat pesat dan hal ini berpengaruh terhadap berbagai aspek pekerjaan, ilmu pengetahuan dan teknologi. Sehingga saat ini sebagian besar perusahaan memilih untuk mengadopsi IS/IT sebagai pendukung kegiatan bisnis. SI/TI tidak lagi dipandang sebagai pelengkap, tetapi telah menjadi penentu terlaksananya sasaran/strategi bisnis perusahaan. Strategi dan Investasi IS/IT adalah kunci agar perusahaan mampu bertahan di lingkungan bisnis yang kompetitif, dan dapat meningkatkan efisiensi serta keefektifan dalam menjalankan aktivitas bisnisnya. IS/IT kemudian mulai diterapkan dan dilibatkan dalam setiap proses bisnis yang ada, namun semuanya harus direncanakan secara matang, hal ini dikarenakan penerapan SI/TI membutuhkan perencanaan dan peninjauan kesiapan dari berbagai aspek serta penyususan strategi yang terpadu [1].

Saat ini permasalahan yang ditemui yaitu tersebarnya data dan informasi dihampir semua divisi atau aspek bisnis serta tidak ada jaminan bahwa informasi dikelola dengan baik. Hal ini menimbulkan fraud yang dilakukan oleh pegawai perusahaan, dimana fraud tersebut berkaitan dengan penggelapan dana akibat tidak terjadi pelaporan data pembelian senilai \pm 3 Milliar Rupiah dengan laporan nomor polisi LP/L/189/IX/2016/SPKT tanggal 17 September 2016 tentang tindak Pidana penipuan dan penggelapan[2]. Sementara pencatatan informasi juga masih mengandalkan aplikasi Ms. Word, Ms. Excel dan Ms. Visio, sehingga sistem harus bekerja dengan cara membaca satu per satu data masukan, untuk dilakukan proses rekap dan konfigurasi, sehingga hal ini menyebabkan waktu dan tenaga yang terpakai cukup banyak. Proses pengumpulan data untuk migrasi data/informasi masih memakan waktu yang lama karena belum adanya sistem yang secara otomatis dapat melakukan pengecekan apakah data-data yang dimasukkan, diproses dan dikeluarkan telah valid. Saat ini, sistem support hanya berfungsi untuk mencatat masalah-masalah yang muncul pasca implementasi sistem, intensitas, waktu dan solusi kemudian hanya untuk keperluan dokumentasi saja, tidak dikembangkan dengan maksimal untuk kepentingan pengembangan kebutuhan di masa depan. Sementara itu pada sistem marketing dan distribusi terdapat beberapa permasalahan, antara lain pencatatan data calon customer dan pendistribusian barang jadi masih menyulitkan untuk dilakukannya data mining dengan berbagai aspek kondisi.

Selain itu proses distribusi barang sering mengalami kendala, karena data dan informasi yang dibutuhkan tersebar pada area-area yang terpisah dan datanya masih belum terverifikasi dengan valid. Begitu pula dengan media branding, saat ini PT. Global Arta Borneo telah menggunakan website, namun masih dinilai kurang efektif, dikarenakan website yang ada fokus pada informasi umum mengenai perusahaan, bukan fokus untuk menjual dan memperkenalkan produk. 


\section{Metode}

Didalam perancangan Perencanaan Strategis SI/TI dibutuhkan suatu framework (kerangka kerja) yang menjadi acuan agar hasil yang diharapkan sesuai dengan kebutuhan, terarah dan tepat sasaran.

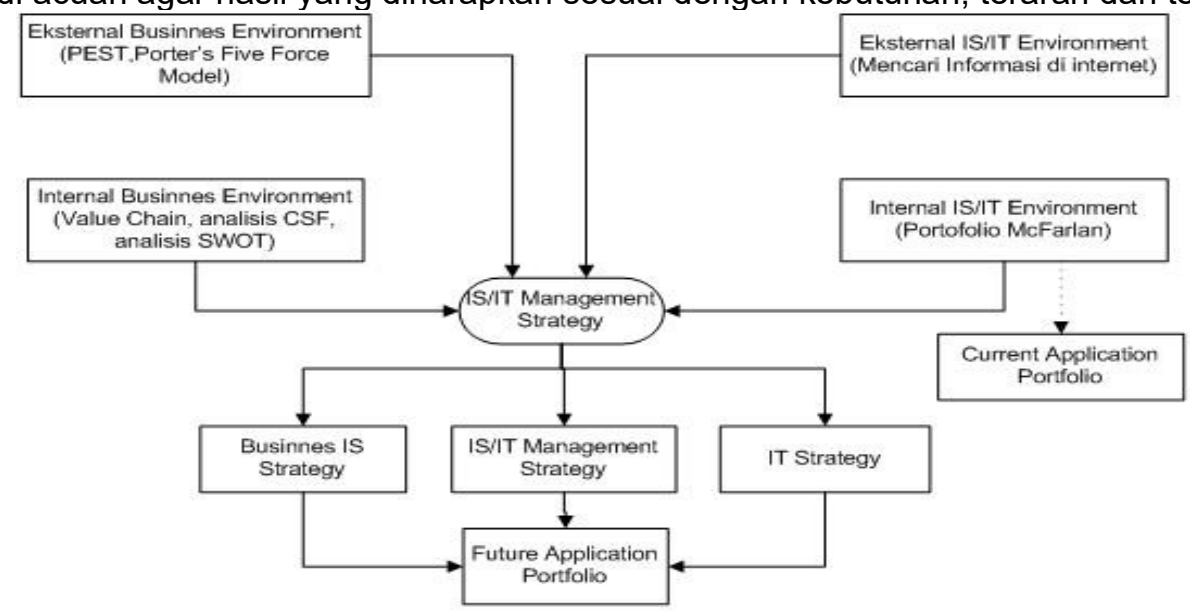

Gambar 1. Model Strategis SI/TI[3]

\subsection{Analisis Critical Success Factor (CSF)}

Hardjanto[4], Setiawan dan IIman [5], serta Wulandari [6] mendefinisikan CSF sebagai area tertentu dalam perusahaan, dimana jika hasil dari area tersebut memuaskan, maka akan menjamin keberhasilan perusahaan dalam bersaing. Area tersebut adalah area kunci dimana "sesuatu harus berjalan dengan baik dan benar" sehingga keberhasilan bisnis dapat dicapai dan terus berkembang.

CSF erat kaitannya dengan Indikator Kinerja Utama/Key Performance Indicator (KPI). Menurut ITGI"s Management Guidelines [7] KPI adalah "a measure of how well the process is performing" dengan kata lain KPI merupakan ukuran-ukuran yang membantu penentuan seberapa baik proses yang diselenggarakan dalam mencapai sasaran. Dalam prakteknya, KPI dan Indikator Tujuan Utama/Key Goal Indicator (KGI) sering membingungkan. KGI sendiri menurut ITGI adalah mengukur tingkat keberhasilan pencapaian dari tujuan.

\subsection{Analisis Rantai Nilai (Value Chain)}

Menurut Michael Porter Value chain analysis adalah kegiatan menganalisis kumpulan aktivitas yang dilakukan untuk merancang, memproduksi, memasarkan, mengantarkan dan mendukung produk atau jasa [8,9]. Pendekatan rantai nilai (value chain) dibedakan menjadi dua tipe aktivitas bisnis:

a. Aktivitas Utama (Primary Activities)

Aktivitas-aktivitas utama pada perusahaan yang pada akhirnya memberikan kepuasan pada pelanggan. Aktivitas-aktivitas tersebut tidak hanya dilakukan dengan baik, tapi juga harus saling berhubungan dengan efektif jika keseluruhan perfoma bisnis hendak dioptimalkan. Aktivitas utama terdiri dari logistik kedalam (inbound logistic), logistik keluar (outbound logistics), operasi, pemasaran dan penjualan (sales \& marketing) dan pelayanan (services).

b. Aktivitas Pendukung (Support Activities)

Aktivitas-aktivitas yang melengkapi aktivitas utama dengan berbagai fungsi, yaitu kelengkapan infrastruktur perusahaan (firm infrastructure), manajemen sumber daya manusia (human resource management), pengembangan teknologi (technology development) dan pembelian/pengadaan barang (procurement). Dengan konsep rantai nilai ini Porter menjelaskan bahwa setiap mata rantai baik yang utama maupun pendukung dapat menambah nilai dari produk yang dihasilkan.

\subsection{Analisis Lingkungan Politik, Ekonomi, Sosial dan Teknologi (PEST)}

PEST adalah analisis terhadap faktor lingkungan eksternal bisnis yang meliputi bidang politik, ekonomi, sosial dan teknologi [10]. PEST digunakan untuk menilai pasar dari suatu unit bisnis atau unit organisasi. Arah analisis PEST adalah kerangka untuk menilai sebuah situasi, dan menilai strategi atau posisi, arah perusahaan, rencana pemasaran, atau ide. Analisis ini cukup mempengaruhi perusahaan, karena melalui analisis ini dapat diambil suatu peluang atau ancaman baru bagi perusahaanDimana terbagi atas :

a. Politik 
Faktor politik meliputi kebijakan pemerintah, masalah-masalah hukum, serta mencakup aturanaturan formal dan informal dari lingkungan dimana perusahaan melakukan kegiatannya, seperti kebijakan tentang pajak, peraturan ketenagakerjaan, peraturan daerah dan peraturan perdagangan.

b. Ekonomi

Faktor ekonomi meliputi semua faktor yang mempengaruhi daya beli dari pelanggan dan mempengaruhi iklim berbisnis suatu perusahaan, seperti pertumbuhan ekonomi, tingkat suku bunga, standar nilai tukar, maupun tingkat inflasi.

c. Sosial

Faktor sosial meliputi semua faktor yang dapat mempengaruhi kebutuhan dari pelanggan dan mempengaruhi ukuran dari besarnya pangsa pasar yang ada, seperti tingkat pendidikan masyarakat, tingkat pertumbuhan penduduk, kondisi lingkungan sosial, kondisi lingkungan kerja.

d. Teknologi

Faktor teknologi meliputi semua hal yang dapat membantu dalam menghadapi tantangan bisnis dan mendukung efisiensi proses bisnis, seperti aktivitas penelitian dan pengembangan teknologi, automatisasi, kecepatan transfer teknologi.

\subsection{Analisis Porter's Five Forces}

Aspek lingkungan industri akan lebih mengarah pada aspek persaingan di mana bisnis perusahaan berada. Akibatnya faktor-faktor yang mempengaruhi kondisi persaingan, seperti ancaman-ancaman dan kekuatan- kekuatan yang dimiliki perusahaan termasuk kondisi persaingan itu sendiri menjadi perlu untuk dianalisis. Michael E.Porter mengemukakan konsep Competitive Strategy yang menganalisis persaingan bisnis berdasarkan lima aspek utama yang disebut Lima Kekuatan Bersaing[11,12,13].

\subsection{Analisis Portofolio Aplikasi Mcfarlan (Portofolio Aplikasi)}

Portofolio Aplikasi Mcfarlan digunakan untuk menilai kontribusi SI/TI secara keseluruhan dan efeknya terhadap kesuksesan bisnis. Portofolio aplikasi adalah cara untuk membawa bersama sistem informasi yang telah ada, direncanakan dan potensial untuk kemudian menilai kontribusi bisnisnya, umumnya berupa matrik dua-kali-dua, yang merupakan metode sangat popular untuk menjelaskan dampak dari variabel yang tidak berkaitan, namun saling mempengaruhi.[3]

\section{Hasil dan Pembahasan}

\subsection{Hasil Analisis Lingkungan Eksternal Organisasi}

Analisis lingkungan eksternal organisasi merupakan analisis terhadap faktor-faktor eksternal yang mempengaruhi kegiatan bisnis organisasi baik yang mendatangkan dan memperbesar peluang organisasi, maupun ancaman bagi organisasi. Analisis tersebut dapat dilakukan dengan menggunakan teknik analisis Five Force Models dan analisis PEST.

a. Analisis Five Force Models

Analisis Five Force Models ini digunakan untuk mengkaji posisi PT. Global Arta Borneo dibandingkan dengan kekuatan eksternal yang mempengaruhi jalannya proses bisnis pada PT. Global Arta Borneo. Di bawah ini adalah paparan analisis Five Force Models, yaitu :

1. Pesaing Industri ( Rivalry)

Dalam menjalankan kegiatan bisnisnya PT. Global Arta Borneo menghadapi persaingan dengan industri-industri yang sejenis. Pesaing utama dari PT. Global Arta Borneo adalah PT. Pertamina Tbk yang sudah lama berdiri, mempunyai brand yang bagus dan sudah menggunakan fasilitas IT yang modern. Pesaing utama yang lain adalah PT Petronas Niaga Indonesia dan perusahaan industri perminyakan lainnya yang terdaftar dan telah mempunyai fasilitas pengolahan minyak, produk yang dihasilkan cenderung banyak, tidak hanya Marine Gas Oil (MGO) dan Marine Fuel Oil (MFO).

2. Ancaman Produk Pengganti (Threat of subtitutes)

Ancaman produk pengganti bagi PT. Global Arta Borneo adalah Bahan bakar hayati atau Biofuel, merupakan setiap bahan bakar baik padatan, cair maupun gas yang dihasilkan dari bahan-bahan organik. Biofuel dapat dihasilkan secara langsung dari tanaman atau secara tidak langsung dari limbah industri, komersial, domestik atau pertanian. Biofuel dapat menjadi ancaman karena Biofuel menawarkan kemungkinan memproduksi energi tanpa meningkatkan kadar karbon di atmosfer. Hal lain yang menjadi pertimbangan yaitu Mobil berbahan bakar listrik atau sinar matahari yang tidak menggunakan bahan bakar kimia, seperti Solar, dll.

3. Kekuatan Pembeli ( Buyer Power )

Yang dikategorikan sebagai pembeli/pengguna jasa bagi PT. Global Arta Borneo adalah beberapa perusahaan lokal yang tersebar di berbagai kota dan telah melakukan kerjasama serta masyakat umum. Meningkatnya pendapatan dan jumlah masyarakat kelas menengah menambah jumlah konsumen yang bersedia memakai merek asing yang sering dianggap lebih berkualitas. 
4. Kekuatan Pemasok (Supplier Power)

Kekuatan pemasok utama PT. Global Arta Borneo adalah PT. Shell. Selain itu ada pemasok lain seperti peraturan pemerintah yang mengatur tentang regulasi penentuan harga jual bahan bakar sesuai dengan Permen No 4 tahun 2015 [14].

5. Ancaman pendatang baru (Threat of new entrants and entry barriers)

Munculnya perusahaan baru yang memiliki produk penjualan yang sama dengan PT. Global Arta Borneo dan bahkan mempunyai link dan kerjasama (MOU) dengan luar negeri menjadi ancaman/kompetitor yang luar biasa dan harus diwaspadai oleh PT. Global Arta Borneo.

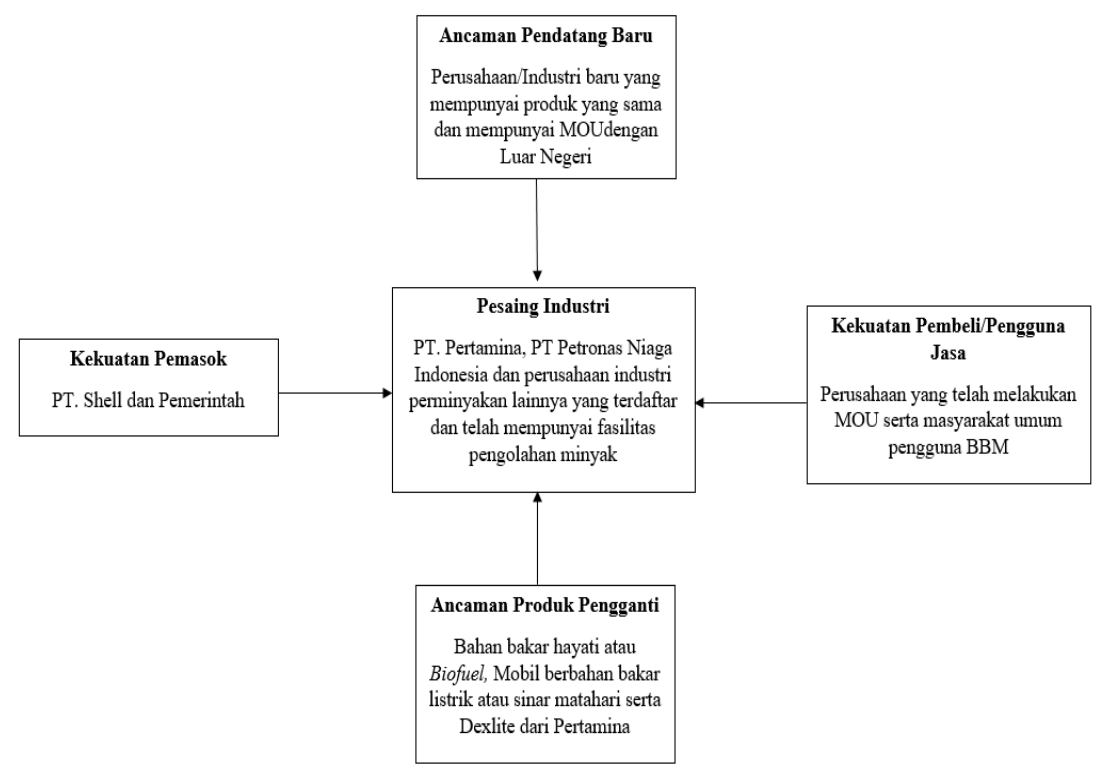

Gambar 3. Porter's Five Forces PT. Global Arta Borneo

b. Analisis PEST

Selain menggunakan analisis Lima Daya Porter untuk mengetahui faktor faktor eksternal perusahaan yang berdampak pada proses bisnis perusahaan, digunakan juga analisis PEST untuk lebih menggali faktor-faktor eksternal lainnya. Faktor-faktor itu meliputi:

1. Faktor Politik

Pengaruh politik yang paling banyak dirasakan pengaruhnya oleh perusahaan adalah dengan adanya Izin usaha perdagangan yang dikeularkan oleh Menteri Energi dan Sumber daya Mineral pada tahun 2007 dengan kode izin usaha 05.NW.03.17.00.012 yang hanya berlaku selama 10 tahun yang berarti berakhir pada tahun 2017 dan harus dilakukan perpanjangan/pembaharuan. Selain itu pengaruh politik lainnya adalah semua produk yang ada dihasilkan PT. Global Arta Borneo harus terstandarisasi berdasarkan kementrian Energi dan Sumber Daya Mineral No: 28.K/10/DJM.T/2016 tentang perubahan kedua atas Keputusan Direktur Jendral Minyak Dan Gas Bumi Nomor 3675.K/24/DJM/2006.

2. Faktor Ekonomi

Efek dari keadaan perekonomian di Indonesia dibedakan menjadi dua yaitu saat keadaan perekonomian dalam dan luar negeri baik dan atau sebaliknya. Aspek yang paling dirasakan adalah fluktuasi nilai tukar rupiah karena semua aktivitasi impor dilakukan dengan menggunakan Kurs Dollar. Di sisi lain regulasi pada pembayaran pajak juga menjadi pengurang pendapatan bagi perusahaan. Pajak yang tinggi akan mengakibatkan perusahaan membatasi pembelian jumlah impor solar.

3. Faktor Sosial

Dalam rangka menjaga hubungan dengan lingkungan sekitar Pelabuhan dan Terminal PT. Global Arta Borneo telah melakukan kegiatan Upaya Pengelolaan Lingkungan (UKL) dan Upaya Pemantauan Lingkungan ( UPL) untuk penerimaan penimbunan dan distribusi BBM dari Ditjen MIGAS dengan No Dokumen 10097/18.05/DMT/2007.

\section{Faktor Teknologi}


Adanya Teknologi berbasis IT berpengaruh pada produktivitas, efektivitas dan efisiensi. Teknologi informasi yang bagus untuk saat ini adalah yang bisa diakses dimana saja dan kapan saja. Teknologi yang memungkinkan hal tersebut yaitu teknologi berbasis web dan online. Oleh karena itu, salah satu teknologi informasi yang dapat digunakan oleh PT. Global Arta Borneo dalam menjalankan fungsi bisnis adalah Semi-Manual.

Tabel 1. Identifikasi Solusi Berdasarkan Analisis PEST

\begin{tabular}{|l|l|l|}
\hline \multicolumn{1}{|c|}{ Faktor PEST } & \multicolumn{1}{c|}{ Kebutuhan Informasi } & \multicolumn{1}{c|}{ Solusi SI } \\
\hline Politik & Standarisasi BBM & SI Penjamin Mutu \\
\hline Ekonomi & $\begin{array}{l}\text { Informasi pembelian dan } \\
\text { pengadaan barang }\end{array}$ & SI SCM \\
\hline Sosial & Rencana Kegiatan CSR & SI CSR \\
\hline Teknologi & Teknologi penjualan online & SI Penjualan \\
\hline
\end{tabular}

\subsection{Hasil Analisis Lingkungan Internal Organisasi}

a. Analisis Value Chain

Analisis Value Chain PT. Global Arta Borneo dilakukan berdasarkan teori Michael Porter. Analisis Value Chain ini memberikan kerangka untuk mengidentifikasi dan menginventarisasikan area-area fungsi bisnis. Area bisnis utama PT. Global Arta Borneo mengacu proses bisnis organisasi yaitu Input, Proses dan Output. Hasil analisis Value Chain PT. Global Arta Borneo dapat dilihat pada tabel berikut ini :

Tabel 2. Identifikasi Solusi SI berdasarkan Value Chain

\begin{tabular}{|c|c|c|c|}
\hline Value Chain & Kegiatan & Unit Kerja & Solusi SI \\
\hline Inbound Logistic & Penerimaan Bahan Baku & $\begin{array}{l}\text { Head Distribusi } \\
\text { Head Operasional }\end{array}$ & SI SCM \\
\hline Operation & $\begin{array}{l}\text { Kegiatan Produksi Bahan Bakar } \\
\text { Minyak }\end{array}$ & Head Operasional & $\begin{array}{l}\text { Bukan Solusi } \\
\text { SI }\end{array}$ \\
\hline Outbund Logistic & Agen retail & Head Marketing & SI CRM \\
\hline Marketing & Kegiatan Sosialisasi dan Promosi & Head Marketing & SI CRM \\
\hline Servicing & $\begin{array}{l}\text { Pelayanan Masyarakat dan Mitra } \\
\text { Kerja }\end{array}$ & Head Marketing & SI CRM \\
\hline Firm Infrastructure & $\begin{array}{l}\text { Unit Keuangan, Floating } \\
\text { Storage,Tanker, Land Craft Tanker, } \\
\text { Oil Barge Mobile,Tugboat dan } \\
\text { Mobil Tanki }\end{array}$ & $\begin{array}{l}\text { Unit finance \& } \\
\text { Accounting, Head } \\
\text { Operasional } \\
\text { danHead Distribusi }\end{array}$ & $\begin{array}{l}\text { SI Keuangan, } \\
\text { SI Sarana } \\
\text { Prasarana, SI } \\
\text { CRM }\end{array}$ \\
\hline $\begin{array}{l}\text { Human Resource } \\
\text { Management }\end{array}$ & $\begin{array}{l}\text { Head Admin (penempatan, } \\
\text { perekrutan, pembinaan, } \\
\text { pengembangan serta } \\
\text { pemberhentian karyawan) }\end{array}$ & Head Admin & $\begin{array}{l}\text { SI } \\
\text { Kepegawaian }\end{array}$ \\
\hline $\begin{array}{l}\text { Technology } \\
\text { Development }\end{array}$ & Jaringan Internet dan Wifi & Head Admin & Bukan Solisi SI \\
\hline Procurement & $\begin{array}{l}\text { Bahan Baku dan pengadaan } \\
\text { sarana prasarana }\end{array}$ & $\begin{array}{l}\text { Head admin dan } \\
\text { Head Operasional }\end{array}$ & $\begin{array}{l}\text { SI sarana dan } \\
\text { prasarana }\end{array}$ \\
\hline
\end{tabular}

\section{b. Analisis CSF}

Analisis CSF melibatkan manajemen senior dalam mengembangkan strategi sistem informasi. Karena CSF secara keseluruhan telah berakar pada bisnis dan memberikan komitmen bagi manajemen puncak dalam menggunakan sistem informasi, yang diselaraskan dengan pencapaian tujuan perusahaan melalui area bisnis yang kritis. Adapun hasil analisis CSF PT. Global Arta Borneo sebagai berikut. 
ILKOM Jurnal IImiah Volume 9 Nomor 2 Agustus 2017

Tabel 3. Matrik Kebutuhan Informasi Bagian Head Marketing PT. Global Arta Borneo

\begin{tabular}{|c|c|c|c|c|}
\hline $\begin{array}{l}\text { Tujuan Head } \\
\text { Marketing }\end{array}$ & $\begin{array}{l}\text { Faktor Penentu } \\
\text { (Critical Sucess } \\
\text { Factor) }\end{array}$ & $\begin{array}{l}\text { KPI (Key } \\
\text { Performance } \\
\text { Indicator) }\end{array}$ & $\begin{array}{l}\text { Value } \\
\text { Chain }\end{array}$ & $\begin{array}{l}\text { Kebutuhan } \\
\text { Informasi }\end{array}$ \\
\hline \multirow{2}{*}{$\begin{array}{l}\text { Membuat program } \\
\text { sosialisasi, } \\
\text { melakukan } \\
\text { penyusunan MoU, } \\
\text { menyediakan } \\
\text { semua informasi } \\
\text { yang dibutuhkan } \\
\text { oleh pelanggan } \\
\text { dan bertanggung } \\
\text { jawab dalam } \\
\text { penerimaan } \\
\text { konsumen baru. }\end{array}$} & $\begin{array}{lr}\text { Membuat } & \text { program } \\
\text { sosialisasi } & \text { dan } \\
\text { promosi PT. Global } \\
\text { Arta Borneo }\end{array}$ & $\begin{array}{l}\text { Pelaksanaan } \\
\text { program sosialisasi \& } \\
\text { promosi berjalan } \\
\text { sesuai rencana }\end{array}$ & Marketing & $\begin{array}{l}\text { Datarasi } \\
\text { tujuan, Data } \\
\text { Mitra } \\
\text { kerja/konsumen }\end{array}$ \\
\hline & $\begin{array}{l}\text { Merencanakan dan } \\
\text { membuat rencana } \\
\text { kegiatan } \\
\text { penerimaan } \\
\text { konsumen baru }\end{array}$ & $\begin{array}{lr}\text { Proses penerimaan } \\
\text { konsumen potensial } \\
\text { baru berjalan } & \text { sesuai } \\
\text { kebijakan } & \text { dan } \\
\text { pedoman } & \text { yang } \\
\text { ditetapkan } & \\
\text { perusahaan } & \end{array}$ & $\begin{array}{l}\text { Inbound } \\
\text { Logistic }\end{array}$ & $\begin{array}{l}\text { Data konsumen } \\
\text { potensial baru, } \\
\text { SOP } \\
\text { penerimaan } \\
\text { konsumen/mitra } \\
\text { kerja baru. }\end{array}$ \\
\hline $\begin{array}{l}\text { Riset kepada } \\
\text { masyarakat untuk } \\
\text { mendukung } \\
\text { kebijaksanaan } \\
\text { pemerintah }\end{array}$ & $\begin{array}{l}\text { Melakukan seluruh } \\
\text { kegiatan penelitian } \\
\text { ( survei) }\end{array}$ & $\begin{array}{lr}\text { Penelitian } & \text { (survei) } \\
\text { yang } & \text { dilakukan } \\
\text { sesuai roadmap dan } \\
\text { kebijakan } & \text { survei } \\
\text { yang } & \text { dibuat } \\
\text { perusahaan } & \end{array}$ & Marketing & $\begin{array}{lr}\text { Data } & \text { lokasi } \\
\text { tujuan, Data } \\
\text { Mitra } \\
\text { kerja/konsumen }\end{array}$ \\
\hline
\end{tabular}

Tabel 4. Matrik Kebutuhan Informasi Bagian Head Operasional \& Safety PT. Global Arta Borneo

\begin{tabular}{|c|c|c|c|c|}
\hline $\begin{array}{l}\text { Tujuan Head } \\
\text { Operasional \& Safety }\end{array}$ & $\begin{array}{l}\text { Faktor Penentu } \\
\text { (Critical Sucess } \\
\quad \text { Factor) }\end{array}$ & $\begin{array}{c}\text { KPI (Key Performance } \\
\text { Indicator) }\end{array}$ & Value Chain & $\begin{array}{l}\text { Kebutuhan } \\
\text { Informasi }\end{array}$ \\
\hline \multirow[t]{2}{*}{$\begin{array}{l}\text { Memberikan } \\
\text { pelayanan kepada } \\
\text { karyawan melalui } \\
\text { program-program } \\
\text { pelatihan dan } \\
\text { pengembangan } \\
\text { produk. }\end{array}$} & $\begin{array}{l}\text { Merencanakan dan } \\
\text { menyelenggarakan } \\
\text { kegiatan program- } \\
\text { program pelatihan } \\
\text { dan } \\
\text { pengembangan } \\
\text { terkait } \quad \text { aspek } \\
\text { produk. }\end{array}$ & $\begin{array}{ll}\text { Proses } & \text { kegiatan } \\
\text { dan program- } & \\
\text { program pelatihan } \\
\text { yang berada di } \\
\text { Bagian Marketing }\end{array}$ & Operation & $\begin{array}{l}\text { Jadwal } \\
\text { kegiatan } \\
\text { produksi, } \\
\text { Jenis program } \\
\text { pelatihan }\end{array}$ \\
\hline & $\begin{array}{l}\text { Evaluasi seluruh } \\
\text { kegiatan } \\
\text { operasional } \\
\text { perusahaan }\end{array}$ & $\begin{array}{l}\text { Monitoring terhadap } \\
\text { operasional } \\
\text { perusahaan } \\
\text { dilakukan sesuai } \\
\text { pedoman }\end{array}$ & Operation & $\begin{array}{l}\text { Informasi } \\
\text { perubahan } \\
\text { jadwal } \\
\text { produksi }\end{array}$ \\
\hline $\begin{array}{lr}\text { Melaksanakan } & \\
\text { kegiatan } & \text { yang } \\
\text { berkaitan } & \text { dengan } \\
\text { keamanan } & \text { dan } \\
\text { keselamatan } & \text { proses } \\
\text { produksi. } & \end{array}$ & \begin{tabular}{l}
\multicolumn{2}{l}{ Melaksanakan } \\
kegiatan yang \\
berkaitan dengan \\
keamanan dan \\
keselamatan \\
proses produksi.
\end{tabular} & $\begin{array}{l}\text { Melaksanakan } \\
\text { kegiatan keamanan } \\
\text { dan keselamatan. }\end{array}$ & $\begin{array}{c}\text { Servicing } \\
\text { dan Human } \\
\text { Resource } \\
\text { Management }\end{array}$ & $\begin{array}{l}\text { Data } \\
\text { karyawan dan } \\
\text { SOP yang } \\
\text { diterapkan } \\
\text { perusahaan }\end{array}$ \\
\hline
\end{tabular}


ILKOM Jurnal IImiah Volume 9 Nomor 2 Agustus 2017

Tabel 5. Matrik Kebutuhan Informasi Bagian Head Distribusi PT. Global Arta Borneo

\begin{tabular}{|c|c|c|c|c|}
\hline $\begin{array}{l}\text { Tujuan Head } \\
\text { Distribusi }\end{array}$ & $\begin{array}{c}\text { Faktor Penentu } \\
\text { (Critical Sucess } \\
\text { Factor) }\end{array}$ & $\begin{array}{c}\text { KPI (Key Performance } \\
\text { Indicator) }\end{array}$ & Value Chain & $\begin{array}{l}\text { Kebutuhan } \\
\text { Informasi }\end{array}$ \\
\hline \multirow{2}{*}{$\begin{array}{l}\text { Memberikan } \\
\text { layanan distribusi } \\
\text { yang berkualitas } \\
\text { kepada Organisasi/ } \\
\text { masyarakat }\end{array}$} & $\begin{array}{l}\text { Merencanakan dan } \\
\text { menyelenggarakan } \\
\text { seluruh kegiatan } \\
\text { disribusi Bahan } \\
\text { Bakar Minyak }\end{array}$ & $\begin{array}{lr}\text { Proses } & \text { kegiatan } \\
\text { distribusi } & \text { Bahan } \\
\text { Bakar } & \text { berjalan } \\
\text { sesuai target } & \text { yang } \\
\text { ditentukan } & \text { PT. } \\
\text { Global Arta } & \text { Borneo. }\end{array}$ & Operation & $\begin{array}{l}\text { Jadwal } \\
\text { kegiatan } \\
\text { distribusi, } \\
\text { Rencana target } \\
\text { yang akan } \\
\text { dicapai }\end{array}$ \\
\hline & $\begin{array}{l}\text { Evaluasi seluruh } \\
\text { kegiatan Distribusi } \\
\text { Bahan Bakar }\end{array}$ & \begin{tabular}{lr} 
Monitoring & terhadap \\
seluruh & kegiatan \\
distribusi & Bahan \\
Bakar & dilakukan \\
\multicolumn{2}{l}{ sesuai pedoman }
\end{tabular} & Operation & $\begin{array}{l}\text { Data karyawan, } \\
\text { data kegiatan } \\
\text { distribusi }\end{array}$ \\
\hline $\begin{array}{l}\text { Mendukung proses } \\
\text { kegiatan distribusi } \\
\text { Bahan Bakar }\end{array}$ & $\begin{array}{l}\text { Menyelenggarakan } \\
\text { proses } \\
\text { penyusunan } \\
\text { distribusi Bahan } \\
\text { Bakar PT. Global } \\
\text { Arta Borneo. }\end{array}$ & $\begin{array}{l}\text { Proses penyusunan } \\
\text { distribusi Bahan Bakar } \\
\text { berjalan sesuai standar } \\
\text { pedoman yang baku }\end{array}$ & $\begin{array}{c}\text { Firm } \\
\text { Infrastructure }\end{array}$ & $\begin{array}{l}\text { Informasi SOP } \\
\text { setiap unit kerja } \\
\text { Sesuai } \\
\text { Kebijakan } \\
\text { Perusahaan }\end{array}$ \\
\hline
\end{tabular}

a. Analisis Kondisi IS/IT Internal

Data yang diperoleh wawancara dipetakan sesuai fungsinya masing-masing menggunakan matriks Mc Farlan's Strategic Grid guna mengetahui prioritas pengembangan sumber daya yang akan diterapkan di PT. Global Arta borneo. Pemetaan dilakukan pada empat kuadran yaitu strategic, high potential, key operation, dan support [3]. Dari hasil pemetaan yang dapat dilihat pada Gambar 3 maka diperoleh portofolio Perencanaan Pengembangan Sumber Daya IS/IT.

\begin{tabular}{|l|l|l|l|}
\hline \multicolumn{2}{|c|}{ Strategic } & \multicolumn{1}{c|}{ High Potential } \\
\hline $\begin{array}{l}\text { SI CRM } \\
\text { SI CSR } \\
\text { SI Penjamin Mutu }\end{array}$ & $\begin{array}{l}\text { Baru } \\
\text { Baru } \\
\text { Baru }\end{array}$ & SI Penjualan & Baru \\
\hline \multicolumn{2}{|c|}{ Key Operational } & \multicolumn{1}{c|}{ Support } \\
\hline SI Penerimaan konsumen Baru & Baru & $\begin{array}{l}\text { SI Sarana dan Prasarana } \\
\text { SI Keuangan } \\
\text { SI Kepegawaian } \\
\text { SI K3 } \\
\text { Website PT. Global Arta Borneo } \\
\text { SI SCM }\end{array}$ & $\begin{array}{l}\text { Baru } \\
\text { Bdaru } \\
\text { Baru }\end{array}$ \\
\hline
\end{tabular}

Gambar 3. Kategori Aplikasi Portofolio Mendatang PT. Global Arta Borneo

Berdasarkan hasil analisis diatas Adapun waktu yang direncanakan dalam kurun waktu 4 tahun (2017-2021). Berikut jadwal implementasi yang akan direncanakan berdasarkan wawancara dengan para Direktur Finance \& Admin serta Direktur Operastional, Logisti \& Marketing PT. Global Arta Borneo: 
Tabel 6. Roadmap Perencanaan Pengembangan SI/TI

\begin{tabular}{|c|l|c|c|c|c|c|}
\hline No & \multicolumn{1}{|c|}{ Rencana Kegiatan } & $\begin{array}{c}\text { Tahun } \\
2017\end{array}$ & $\begin{array}{c}\text { Tahun } \\
2018\end{array}$ & $\begin{array}{c}\text { Tahun } \\
2019\end{array}$ & $\begin{array}{c}\text { Tahun } \\
2020\end{array}$ & $\begin{array}{c}\text { Tahun } \\
2021\end{array}$ \\
\hline 1. & SI CRM & & & & & \\
\hline 2. & SI CSR & & & & & \\
\hline 3. & SI Penjamin Mutu & & & & & \\
\hline 4. & SI Penerimaan konsumen Baru & & & & & \\
\hline 5. & SI Penjualan & & & & & \\
\hline 6. & SI Sarana dan Prasarana & & & & & \\
\hline 7. & SI Keuangan & & & & & \\
\hline 8. & SI Kepegawaian & & & & & \\
\hline 9. & SI K3 & & & & & \\
\hline 10. & SI SCM & & & & & \\
\hline
\end{tabular}

\section{Kesimpulan dan saran}

\subsection{Kesimpulan}

Berdasarkan hasil pembahasan yang telah dilakukan, peneliti memberikan rekomendasi kepada PT. Global Arta Borneo yaitu terdapat 10 strategi Rencana kegiatan diantaranya SI CRM, SI CSR, SI Penjamin Mutu, SI Penerimaan Konsumen Baru, SI Penjualan, SI Sarana dan Prasarana, SI Keuangan, SI kepegawaian, SI K3 dan SI SCM yang akan diimplementasikan selama 5 tahun untuk menunjang proses bisnis PT. Global Arta Borneo yang dapat memiliki keunggulan, kompetitif dan meningkatkan daya saing.

\subsection{Saran}

Berikut adalah saran agar penelitian berikutnya yang akan melakukan penelitian yang sama, agar mendapatkan hasil yang lebih baik:

1. Pada penelitian ini fokusnya hanya pada arsitektur Bisnis perusahaan, untuk penelitian yang akan datang bisa dilakukan pada arsitektur infrastruktur, informasi, aplikasi dan tata kelola IT.

2. Agar lebih spesifik lagi bisa dilakukan analisis kelayakan investasi atas perencanaan strategis $\mathrm{SI} / \mathrm{TI}$ serta membuat analisis perencanaan biaya.

3. Pada penelitian yang akan datang bisa dilakukan pengujian efektifitas penerapan IT/SI sebelum yang sesudah impementasi masterplan.

4. Mengkombinasikan berbagai alat analisis seperti Generic Strategic Michael Porter berupa fokus strategi cost leadership, Differentiation, Cost Focus, Differentation Focus serta Stuck in The Middle.

\section{Daftar Pustaka}

[1] Esson Sihombing. 2014. Future Business Analysis and Mapping Dalam Perancangan IS/IT Strategic Planning Pada PTRH. Thesis UNIKOM

[2] Banjarmasin Post. ASN Puskesmas Seruyan Ditangkap Gelapkan Rp 3 Miliar Uang Penjualan Solar PT Global Arta Borneo. Diakses dari https://goo.gl/jviffL pada tanggal 3 April 2017 Jam $17.00 \mathrm{WIB}$.

[3] Ward, John, Peppard, Joe. 2002. Strategic Planning For Information System. 3rd Edition. John Willey \& Sons, Buffins Lane, Chichester. E-BOOK diakses dari https://goo.gl/7yY5PR pada tanggal 3 April 2017 Jam 09.00 WIB.

[4] Hardjanto, Kurnia. 2015. Strategic Planning of Information Systems at Department of Agriculture, Animal Husbandry and Fisheries Magelang with Ward and Peppard Framework. Jurnal Teknologi Informasi dan Komunikasi. Vol. 4 No.2, Desember 2015 : 88 - 99

[5] Setiawan Awan dan IIman Benie. 2012. Perencanaan Strategik Sistem Informasi pada Perusahaan Penerbitan dengan Metode Ward and Preppard: Studi Kasus pada Penerbit Rekayasa Sains Bandung. Jurnal Manajemen Teknologi. Volume 11 Number 32012

[6] Wulandari, Dewi Ayu Nur. 2014. Perencanaan Strategis SI/TI Dengan Menggunakan Metodologi Tozer Pada BMT Salsabila Jakarta. Jurnal Sistem Informasi stmik Antar Bangsa. Vol. III No.2 Agustus 2014 
[7] Guldentops, E., Van Grembergen, W., \& De Haes, S. 2002. Control and governance maturity survey: establishing a reference benchmark and a self-assessment tool. Information Systems Control Journal, 6, 32-32.

[8] Masniah. 2015. Perencanaan Strategis Sistem Informasi Apotek Mutiara Insani Martapura kalimantan selatan. Journal Speed - Sentra Penelitian Engineering dan Edukasi Volume 7 No 4 2015

[9] Haron, Haryani dan Zolkarnain, Zulfadhli Naim. 2013. A Situational Analysis of Strategic Information System Planning in the Context of a Malaysian SME. 3rd International Conference on Research and Innovation in Information Systems.

[10]Fahana, Jefree., Utami, Ema dan Amborowati, Armadyah. 2016. Perencanaan Strategis Sistem Informasi Untuk Pengelolaan Kepemimpinan Di Sekolah Muhammadiyah Kota Yogyakarta. Jurnal IImiah DASI Vol. 17 No. 2 Juni 2016 ISSN: 1411-3201

[11] Husain Umar. 2005. Manajemen Riset dan Perilaku Konsumen. PT. Gramedia Pusat: Jakarta

[12] Masniah. 2015. Perencanaan Strategis Sistem Informasi Apotek Mutiara Insani Martapura kalimantan selatan. Journal Speed - Sentra Penelitian Engineering dan Edukasi Volume 7 No 4 2015

[13] Kusuma, Erwin Arry. 2016. Perencanaan Strategis Sistem Informasi PT. Anugerah Aulia Alam Raya Pengembang Perumahan Banjarbaru Kalimantan Selatan. Jurnal Evolusi Volume 4 Nomor $1-2016$

[14]Departemen ESDM. Peraturan Mentri Energi Dan Sumber Daya Mineral Republik Indonesia No 4 Tahun 2015 Tentang Perhitungan Harga Jual Eceran bahan Bakar Minyak. 